\title{
The Message Influences Me More Than Others: Social Media Metrics, Third-Person Perception, and Behavioral Intentions
}

\author{
Myojung Chung \\ University of San Francisco \\ mchung11@usfca.edu
}

\begin{abstract}
This study examines how the presence of social media metrics affect perceived media influence on self and others (Third-Person Perception) and subsequent behavioral intentions to combat an environmental risk. In a between-subjects experiment $(N=241)$, participants read an article about climate change with or without social media metrics. Results suggest that (a) the presence of social media metrics reverses TPP, (b) social media metrics increase compliant behavioral intentions through mediation by TPP, and (c) need to belong moderates the effects of social media metrics on TPP. Theoretical and practical implications are discussed.
\end{abstract}

\section{Introduction}

On typical websites today, various cues allow us to learn how other readers think about the media messages that we are reading $[1,2,3]$. Social media metrics (i.e., how many people shared the media message) serve as a good example of these cues. Often displayed alongside online media messages, social media metrics indicates how popular or viral a specific media message is $[4,5]$. Many studies have illuminated how this information from other readers affect the way people process media messages [4, 5, 6, 7].

Extending this line of research, this study examines social media metrics effects through the lens of Thirdperson effect (TPE, hereafter). TPE refers to the perceptual discrepancy between self and others regarding media effects and its behavioral outcomes; people tend to assume others are more susceptible to persuasive media message than they are. As a result of this perception, people take actions to prevent the message's influence [8]. Departing from the traditional approach to TPE that focused on the traditional context, a growing body of research has explored how the digital media setting affects perceived influence of media on self and others [4, 9, 10, 11] - namely, Web thirdperson effect (WTPE). However, research on the link between social media metrics and WTPE is limited, and the findings are inconsistent. It leads to the following questions: How does social media metrics shape perceived media effects on self and others? How does the perception influence behavioral intentions? What factors affect the strength of social media metrics in shaping message perception and attitudes?

To seek answers to these questions, this study employs a between-subjects experiment in which the presence of social media metrics was manipulated (absent vs. present). Drawing on TPE, this study first examines how the presence of social media metrics affects perceived media influence on self and others (Third-Person Perception, TPP), and how this perception forms behavioral intentions to adopt the recommendations in the media message. Finally, this study examines the role of the need to belong as a potential moderator of social media metrics effects on TPP and behavioral intentions. Given the growing role of social media in various forms of communication, this approach will provide meaningful insights for communication scholars and practitioners into how to design and deliver persuasive messages more effectively in the digital era.

\section{Literature Review}

\subsection{Social media metrics}

Online content providers have increasingly incorporated technology designed to allow users to express their opinions about specific media contents and related issues. Social media metrics is one of the signature characteristics of digital media content. Displaying the number of times a certain media content has been shared via social media, social media metrics were originally employed for increased audience engagement as well as increased web traffic [3]. Many news organizations use social media metrics not only for editorial decision-making, but also for evaluations of journalists' performance [12].

However, the role of social media metrics have expanded beyond a tool to increase web traffic or to make journalistic decisions or evaluations. A growing number of studies have discussed what psychological implications social media metrics may have for message consumers. For instance, KnoblochWesterwick and her colleagues [6] found that people select a specific online news article more if the article has received explicit recommendations from other readers. Also, the stronger explicit recommendations 
were, the longer exposure time was for the news article. Lee-Won et al. [5] also observed that a large number of social media metrics displayed alongside an online solicitation message for bone marrow donation induce stronger behavioral intention to join a bone marrow registry.

These findings suggest that social media metrics function as cues for message recipients. As an indication of popularity or virality of a specific media content $[4,5]$, social media metrics may indicate that other readers endorse the media message to some extent; people often share content they find interesting or important through social media such as Facebook, Twitter, and Google+ [5]. In this vein, it is reasonable to expect that social media metrics affect not only how people perceive media content, but also the way they perceive the influence of content [4]. This notion is central to the current study, and it seeks to examine how social media metrics affect perceptions of message influence on self and others.

\subsection{Social media metrics and TPP}

The third-person effect hypothesis has two key components: the perceptual component and the behavioral component. The former focuses on the perceptual self-other discrepancy (TPP); people tend to perceive that persuasive media messages have a greater influence on others as compared to on themselves. The later focuses on the behavioral consequences that may result from these perception gaps. For instance, when asked to estimate the effects of violent or misogynistic lyrics from rap music, people perceived that others were more easily influenced by the lyrics than themselves. This perception, in turn, led people to take actions, such as censorship, to counteract the impact [13].

Since sociologist Davison proposed TPE [8], researchers from diverse fields in social sciences have examined TPP in a wide range of contexts such as news [14], commercial content [15], health messages [16], entertainment [17, 18], and political communication [19]. A meta-analysis of 106 studies found that the average effect size of TPP is $d=.646(r=.307)$, which is quite robust [20].

The fundamental premise of TPP is a lack of knowledge about how others perceive a specific media message. In the traditional media context (i.e., reading newspapers or watching television news), audiences did not have any direct information about how other audiences think about or react to the media content. Scholars have investigated how this ignorance influence media effects and found that people tend to presume the potential effects of media on other people. This presumption, in turn, triggers changes in their attitudes or behaviors to counterbalance the media effects on others [21, 22].

However, the development of the Internet has significantly changed the context in which people consume media messages [7]. Since digital content often incorporates direct user feedback tools such as social media metrics, audiences are now easily informed about how others think about and react to the media messages $[6,10]$. This information removes audiences' ignorance, and thus may profoundly alter the formation of TPP.

A growing number of studies have explored how social media metrics affects TPP, but the findings are inconsistent. Antonopoulos and colleagues [23] found that people believe others are more influenced by social media metrics than themselves. On the contrary, Stavrositu and Kim [4] observed that TPP is conditional upon the level of social media metrics; when reading a news article with low social media metrics (i.e., small number of sharing via social media), people perceived that the article would have stronger influence on others than on self, confirming a classic TPP. In contrast, with high social media metrics (i.e., large number of sharing via social media), the self-other discrepancy was diminished to insignificant levels.

Extending this line of research and clarifying the role of social media metrics on TPP, this study explores how the presence of social media affect TPP. As a cue indicating popularity or virality of a media content $[4$ 5], social media metrics may indicate the level of acceptance of specific perspectives or behaviors mentioned in the media message. In other words, other readers' positive reactions to the media could signal social norms [24], which in turn may affect people's perceptions and behaviors [5, 6, 24].

In this vein, this study predicts that the presence of social media metrics serves to reduce TPP. Bandwagon effect, referring to a psychological phenomenon whereby people do something following others' action, regardless of their own beliefs [25, 26], provides a theoretical explanation for this prediction. Bandwagon effect postulates that when many people endorse a certain stance or object, individuals tend to take it as an indicator of social norms and thus they are more likely to jump on the bandwagon (i.e. "If other people like it, then I should like it, too.") [27].

Past studies suggest that audience reactions to media content can communicate injunctive norms people's beliefs regarding what is approved by others and what ought to be done [28]. A more recent study [5] also showed that high social media metrics lead to a greater perception of injunctive norms regarding bonemarrow donation as compared to low social media metrics. In the present study, the presence of social media metrics may signal that many people believe the climate change issue is important and preventive actions ought to be taken. This perception may heighten perceptions of injunctive norms in favor of the recommended preventive actions in the article.

In light of this discussion, and consistent with a previous study pertaining to the social media metrics effect on TPP [4], the current study predicts that the presence of social media metrics is likely to increase the normative appeal of the story and thus lead audiences to want to "jump on the bandwagon" just like others. 
Through this process, the social distance between the self and others may be reduced, which will, in turn, lead to similar assessments of media influence on self and others.

H1: When there is social media metrics alongside a media message, TPP will decrease.

\subsection{Social media metrics, TPP, and behavioral consequences}

The second component of TPE focuses on the behavioral consequences that may result from the perception gaps (TPP). Scholars have discussed two different types of behavioral outcomes of TPP defiance and compliance [4, 29]. Research has found people take defiant actions on the third-person perceptual gaps to prevent the impact of undesirable media messages. For example, McLeod, Eveland, and Nathanson [13] found that college students who perceive misogynic rap lyrics to have negative influences on others as compared to themselves tend to support censorship of such lyrics.

On the contrary, when people find media messages desirable, TPP may induce compliant actions. Tewksbury, Moy, and Weis [30] found that TPP is negatively associated with behavioral intentions to take precautionary actions in preparation for the millennium bug $(\mathrm{Y} 2 \mathrm{~K})$; when people perceive that the $\mathrm{Y} 2 \mathrm{~K}$ news has a greater influence on others (vs. self), they were less likely to adopt preventive measures. Similarly, Wei et al. [31] discovered a negative association between TPP and compliant behavioral intentions. The authors showed that the stronger the perceived influence of avian flu news coverage on others (vs. self), the weaker the audiences' intentions to seek more information about flu risks or to get vaccinated. However, diminished or reversed TPP (i.e., people perceive that the message has similar or more influence on themselves than on others) led to stronger intentions to adopt preventive measures.

In this vein, it is reasonable to expect that the social media metrics displayed alongside news stories would influence behavioral intentions, via mediation by TPP. Specifically, given that media messages addressing an environmental issue (climate change) and suggesting how to combat such problems are likely to be perceived as a desirable message, this study predicts that reduced TPP by the presence of social media metrics (as hypothesized in H1) will increase compliant behavioral intentions.

H2: Behavioral intentions to adopt preventive actions will be stronger among participants in the social media metrics condition compared to those in the no social media metrics condition.

H3: The relationship in $\mathrm{H} 2$ will be mediated by TPP; the presence of social media metrics will reduce TPP, and reduced TPP will, in turn, lead to stronger behavioral intention.

\subsection{Need to belong as a moderator}

The presence of social media metrics may not uniformly influence all the readers' TPP. There can be factors that may alter the direction and the magnitude of the social media metrics effects. Many scholars have illuminated existing tendency, beliefs, and knowledge as audience-level factors that moderate the effects of media messages [3, 32, 33].

This study focuses on the need to belong as a potential moderator of social media metrics effects on TPP. As a fundamental human need to form and maintain lasting, positive, and significant interpersonal relationship [34], the need to belong provides an apt context for examining how audiences' existing tendency moderate the effects of social media metrics on TPP. Prior research demonstrated that those high in the need to belong are more likely to "jump on the bandwagon" as they take others positive reaction as norms to follow [35]. Another study showed that individuals with a strong need to belong demonstrate enhanced sensitivity to social cues in a message [36].

Thus, it is reasonable to expect that the social media metrics effects on TPP may vary depending on individuals' need to belong. On the one hand, those high in the need to belong may pay closer attention to social media metrics as they want to know the social norms (i.e., what others approve or believe to be important) and conform to the norms. Consequently, they are more likely to be influenced by the presence of social media metrics when estimating media influence on self and others. On the other hand, those low in need to belong may be less likely to care about others' thoughts or reactions and thus less influenced by the presence of social media metrics. Due to limited empirical research in this area, this study proposes the following research question.

RQ: Will the social media metrics effects on TPP be moderated by the need to belong? If so, how?

\section{Methods}

\subsection{Design and Procedure}

This study employs a between-subjects experimental design. Study participants read a news story about climate change, with or without social media metrics (present vs. absent). Once participants clicked a link on the recruitment post, they were directed to the online experiment. After providing consent, participants were randomly assigned to one of the two conditions: Social media metrics condition $(\mathrm{n}=$ $114)$ and no social media metrics condition $(n=127)$. After reading the stories, participants were asked a series of questions, as detailed below. When the participants completed the questionnaire, they were 
informed that the news story they read was based on actual news stories but modified.

\subsection{Participants}

This study recruited participants using the subject pool system at a large university in Singapore. The students received extra credit for participating in a study described as being about "online news processing" in October 2016. 241 undergraduate and graduate students participated in this study (Female $=$ $78.8 \%$, Male $=21.2 \%, \mathrm{M}$ age $=20.83, \mathrm{SD}=2.37)$. The imbalanced gender proportion reflects the male to female ration in the subject pool. Ethnicity characteristics included $91.7 \%$ Chinese, $3.3 \%$ Malay, $2.9 \%$ Indian, and $2.1 \%$ others.

Using a series of analysis of variance (ANOVA) and chi-square tests, I found no significant demographic difference between conditions, $\mathrm{p}=.848$ (age), $\mathrm{p}=.326$ (gender), $\mathrm{p}=.422$ (ethnicity). Thus, randomization was deemed successful.

\subsection{Stimulus}

A news story about climate change and prevention served as the basis for the two experimental conditions in this study. The story, titled "Climate change could make the earth uninhabitable," started with a paragraph summarizing researchers' findings of how climate change can negatively influence people around the globe. Then, it detailed the data regarding climate change such as increasing number of extremely hot days in various countries and increased likeliness of downpours. The story concluded with simple lifestyle strategies everyone could adopt to combat climate become informed about climate change, change the most-used light bulbs to Energy-efficient labeled products, set electronic equipment power down when not using them, recycle and reuse, reduce water waste, and use public transportation. To increase the authenticity of the language and tone of the stories, an experienced journalist created the news story.

The news story was formatted as a feature on a fictitious environment news blog and was embedded in the online survey in the form of a screenshot (Figure 1). Perceived realism of the mock-up page was assessed by three items (i.e., "the website is realistic," "the media content is realistic") on a 9 point-scale ranging from 1 (strongly disagree) to 9 (strongly agree). The web page was rated as fairly realistic $(\mathrm{M}=7.06, \mathrm{SD}=1.41, \alpha=$ 93). The news story was identical across the two experimental conditions, except for the social media metrics manipulation. To achieve this manipulation, the story in the social media metrics condition was accompanied by four social media metric icons (Facebook, Twitter, Google+, and email) displayed underneath the title as well as on the left bottom of the article. The icons displayed 2,823 shares in total. The specific number of social media metrics was determined by monitoring the typical number of high social media metrics in several environmental news blogs (i.e., earthtimes.org, theguardian.com) over a three-day period. In the no social metrics condition, there were no icons and numbers displayed.

\subsection{Measures}

\subsubsection{Perceived media influence on self and others}

To assess perceived influence of the news story and self, participants were asked to indicate (a) whether the story had an influence on "you," (b) whether the story made "you" more concerned about climate change, and (c) whether the story made "you" to take climate change more seriously $(1=$ not at all, $7=$ very much, $M$ $=4.27, \mathrm{SD}=1.38, \alpha=.95)$. Perceived influence on others was measured using the same three items as above, with "you" replaced by "others" $(\mathrm{M}=4.28, \mathrm{SD}$ $=1.24, \alpha=.96)$. Then a TPP indicator was computed based on the traditional subtractive method (i.e., perceived influence on others - perceived influence on self; $\mathrm{M}=.02, \mathrm{SD}=1.02$ ).

\subsubsection{Behavioral intentions}

To measure behavioral intentions, participants rated their likelihood of engaging in the lifestyle strategies mentioned in the news story in the next 30 days on a 9point Likert scale ( $1=$ not at all, $9=$ very much). A higher mean score indicates stronger behavioral intentions to adopt the lifestyle strategies to combat climate change $(\mathrm{M}=5.14, \mathrm{SD}=1.62, \alpha=.87)$.

\subsubsection{Need to belong}

Need to belong was assessed using ten items adopted from Leary, Kelly, Cottrell, \& Schreindorfer [37]. Participants indicated to what extent they agreed with proposed statements on a 7-point Likert scale (1 = strongly disagree, $7=$ strongly agree). A higher mean score indicates stronger need to belong $(\mathrm{M}=4.57, \mathrm{SD}$ $=.96, \alpha=.85)$.

\section{Results}

\subsection{Manipulation check}

To confirm that the experimental manipulation performed as intended, participants were asked to indicate to what extent they agree with the following statement: "The news story had a lot of shares" on a 7point Likert scale $(1=$ strongly disagree, $7=$ strongly agree). An independent sample t-test shows that participants in the social media metrics condition indicated that the news story had a significantly larger amount of shares $(\mathrm{M}=4.63, \mathrm{SD}=1.52)$ than as the no social media metrics condition $(\mathrm{M}=4.06, \mathrm{SD}=1.38)$, $\mathrm{t}(239)=3.04, \mathrm{p}<.01$.

\subsection{Hypotheses \& research question testing}


To test $\mathrm{H} 1$ which predicts that TPP will decrease in the presence of social metrics, a 2 (social media metrics: absence vs. presence) x 2 (perceived influence: self vs. others) mixed model repeated measures ANOVA was performed. There was no main effect for self-other ratings, $p=.914$. However, there was a significant self-other ratings $\mathrm{x}$ social media metrics interaction, $\mathrm{F}(1,239)=5.30, \mathrm{p}<.05$, partial $\eta 2=.022$. In the no social media metrics condition, participants perceived that the news story has more influence on others than on self, suggesting a classic TPP. However, when there was social media metrics, TPP not only disappeared but was reversed; participants perceived that they are more influenced by the news story than others (see Figure 2). Hence, H1 was supported.

This study predicted that behavioral intentions would be stronger among participants in the social media metrics condition compared to those in the no social media metrics condition $(\mathrm{H} 2)$, and this social media metrics-behavioral intention relationship will be mediated TPP (H3). A series of ANOVA found no social media metrics condition difference on behavioral intentions $(\mathrm{p}=.32)$. However, presence of social media metrics $(\mathrm{M}=-.14, \mathrm{SD}=.92)$ significantly decreased TPP compared to the no social media metrics condition $(\mathrm{M}=.16, \mathrm{SD}=1.09), \mathrm{F}(1,239)=5.30, \mathrm{p}=.02$, partial $\eta 2=.02$.

Then a mediation model (model 4 ) in the PROCESS macro was tested. Results indicate suggest TPP was negatively associated with behavioral intentions ( $\mathrm{B}=-$ $.24, \mathrm{t}=-2.31, \mathrm{p}=.02)$. The indirect effect of social media metrics on behavioral intentions via TPP was significant $(95 \% \mathrm{CI}=[-.205,-.004])$. Controlling for the mediator, the effect of social media metrics on behavioral intention became insignificant $(\mathrm{B}=.21, \mathrm{t}=$ $.99, \mathrm{p}=.32$ ), suggesting a full mediation via TPP. Thus, $\mathrm{H} 2$ was rejected, and H3 was supported (Figure 3).

RQ explored how the need to belong would moderate the effects of social media metrics on TPP. Using a PROCESS macro (model 1), I tested a simple moderation. TPP was regressed on control variables, social media metrics, need to belong, and their interaction term. None of social media metrics, $\mathrm{B}=-$ $.31, \mathrm{t}=-.47, \mathrm{p}=.636$, need to belong, $\mathrm{B}=-.20, \mathrm{t}=-.88$, $\mathrm{p}=.379$, and their interaction term, $\mathrm{B}=.13, \mathrm{t}=.96, \mathrm{p}$ $=.339$, had significant effect on TPP. However, when the estimated values of TPP were plotted at -1 SD, mean score, and $+1 \mathrm{SD}$ of need to belong $(\mathrm{M}=4.57$, $\mathrm{SD}=.96)$ for each condition of social media metrics (absent vs. present), the social media metrics condition induced significantly lower TPP than the no social media metrics condition, only for those who scored equal or above the mean in need to belong (Figure 4). In other words, those high in need to belong reported significantly weaker TPP when reading a news story with social media metrics (vs. no social media metrics), but those low in need to belong did not show such differentiation.

\section{Discussion}

Departing from traditional discussions on TPE that did not account for all the context that people encounter media messages, this study focused on an online message feature largely unexamined before - social media metrics. The main purpose of this study was to investigate how the presence of social media metrics shape perceived media influence on self and others (TPP) as well as behavioral intentions to adopt the recommendations in a media message. This study also explored the potential role of the need to belong as a moderator of social media metrics effects on TPP.

This approach yielded several interesting findings. First, the data confirm that social media metrics affect how people estimate media influence on self and others. When reading a news article with no social media metrics, participants reported a classic TPP - others are more influenced by the article than themselves. However, when there were social media metrics, TPP was reversed; people perceived that they are more influenced by the article than others. This finding implies that many people indeed view social media metrics as a reflection of social norms regarding a specific perspective or behavior mentioned in a media message.

Secondly, this study found that presence of social media metrics enhanced compliant behavioral intentions, and TPP mediates this link. As discussed above, the presence of social media metrics reversed TPP. This reversed TPP, in turn, increased behavioral intentions to comply with the recommended actions to combat climate change. This finding comports with previous research that suggested a negative association between TPP and compliant behavior intentions when a message is perceived desirable [4, 31, 32].

Another important finding of this study is that the need to belong determines the power of social media metrics effects on TPP. Participants who reported low need to belong were not influenced by the presence of social media metrics in estimating media influence on self and others. In contrast, participants who reported high need to belong were significantly influenced by the presence of social media metrics in their estimation of media influence. Specifically, those high in the need to belong perceived that they were more influenced by the article than others. It is possible that those high in the need to belong felt that other readers who shared the news article were influenced by the story, and thus they want to belong to the "influenced" group. In other words, they want more to "jump" on the social media metrics bandwagon. This finding is in line with prior research that demonstrated the link between the need to belong and the bandwagon effect $[36,37]$. The finding also offers continued support for previous research asserting that audience characteristics play an important role in determining media effects $[3,33,34]$. Although it is beyond the scope of this study, it would be interesting to examine in future research whether and why people perceive "other readers" who shared the 
article differently from "generalized others."

This study makes some meaningful theoretical and practical contributions to the field of communication. Online message consumption behaviors like sharing certain media messages via social media urge scholars and practitioners to take novel perspectives into media effects. In this light, this study provides a more comprehensive understanding of TPP in the digital era. Particularly, given that extant findings of the relationship between social media metrics and TPP are inconsistent [4, 23], this study contributes to clarifying the role of social media metrics in shaping TPP. This study not only provides continued support for previous research stating that social media metrics reduce TPP [4], but also expands extant literature by illuminating how an individual audience's need to belong moderates social media metrics effects. The findings regarding the moderating role of the need to belong highlight the need to carefully analyze traits of the target audience when communicating persuasive messages. As today's communications involve more fragmented and diverse audiences than ever, a more comprehensive understanding of audiences is an essential step to go beyond a conventional framework of persuasive communication.

The findings about social media metrics effects on TPP are also in line with previous research that audience reaction to media content serves as an important indication of social norms [38, 39]. This study demonstrates that as a new form of audience reactions to online media content [40], social media metrics may function as a cue to communicate social norms, which in turn affects perceived media influence on self and others and subsequent behavioral intentions.

Lastly, this study highlights the need for communication practitioners to pay closer attention to the role of social media metrics in designing and distributing messages. For instance, a better understanding of how social media metrics influence TPP and behavioral intentions may help them determine when it would be optimal to juxtapose social media metrics with their messages.

It is important to discuss limitations of this study and to propose better paths for future research. First, this study examined the effects of social media metrics on TPP and subsequent behavioral intentions for a single story. This might limit the findings of this study to a specific context. Future research would benefit from using multiple stories across different topics to find any overarching pattern in social media metrics effects.

Second, because this study used a university student sample in Singapore, some consideration must be given to the possibility that the results of this study are specific to the examined sample. For instance, given that Singapore is a collectivistic society, this particular sample's reaction to social media metrics might be dictated by need to belong more as compared to participants in other individualistic countries such as the U.S. Also, with elderly participants who are not consuming online news often or familiar with social media as compare to university students, the pattern of results can be different. Hence, future studies should expand this line of research beyond this specific demographic group or cultural context.

Third, this study employed aggregated social media metrics (the number of shares via Facebook, Twitter, Google+, and email altogether). The results might present a different picture if specific sharing numbers for respective social media channels were displayed. Also, there may be critical thresholds of the social media metrics level that have an impact on TPP. There also is a possibility that the specific position of social media metrics on the website or the design of the website influence the results. Taken together, additional experiments considering these issues could provide further insights.

Another limitation of this study is that it did not directly measure how participants interpret social media metrics in relation to social norms. Although previous literature has postulated social media metrics as a cue signaling social norm, whether message recipients indeed perceive social media metrics in such a way has not been empirically tested. For instance, if a person perceives that social media metrics reflect general interests of other users but not necessarily social norms, the individual may be less likely to be influenced by social media metrics in terms of perceived media influence on self and others. Hence, future research could involve measuring participants' perception of social media metrics to better examine the mechanism of social media metrics effects on TPP and behavioral intentions.

\section{References}

[1] Chung, M., Munno, G. J., \& Moritz, B. (2015). Triggering participation: Exploring the effects of thirdperson and hostile media perceptions on online participation. Computers in Human Behavior, 53, 452-461.

[2] Chung, M. (2017). Not just numbers: The role of social media metrics in online news evaluations. Computers in Human Behavior, 75, 949-957.

[3] Lee, E. J. (2012). That's not the way it is: How user-generated comments on the news affect perceived media bias. Journal of Computer-Mediated Communication, 18(1), 32-45. [4] Stavrositu, C. D., \& Kim, J. (2014). Social media metrics: Third-person perceptions of health information. Computers in Human Behavior, 35, 61-67.

[5] Lee-Won, R. J., Abo, M. M., Na, K., \& White, T. N. (2016). More than numbers: Effects of social media virality metrics on intention to help unknown others in the context of Bone Marrow donation. Cyberpsychology, Behavior, and Social Networking, 19(6), 404-411.

[6] Knobloch-Westerwick, S., Sharma, N., Hansen, D. L., \& Alter, S. (2005). Impact of popularity indications on readers' selective exposure to online news. Journal of Broadcasting \& Electronic Media, 49(3), 296-313.

[7] Messing, S., \& Westwood, S. J. (2014). Selective exposure in the age of social media: Endorsements trump partisan source affiliation when selecting news online. Communication Research, 41(8), 1042-1063.

[8] Davison, W. P. (1983). The third-person effect in communication. Public Opinion Quarterly, 47, 1-15. 
[9] Chen, G. M., \& Ng, Y. M. M. (2016). Third-person perception of online comments: Civil ones persuade you more than me. Computers in Human Behavior, 55, 736- 742. [10] Houston, J. B., Hansen, G. J., \& Nisbett, G. S. (2011). Influence of user comments on perceptions of media bias and third-person effect in online news. Electronic News, 5(2), 7992.

[11] Schweisberger, V., Billinson, J., \& Chock, T. M.

(2014). Facebook, the Third-Person Effect, and the

Differential Impact Hypothesis. Journal of Computer-

Mediated Communication, 19(3), 403-413.

[12] Cherubini, F., \& Nielsen, R. (2016). Editorial analytics: How news media are developing and using audience data and metrics. Digital News Project 2016, Reuters Institute for the Studies of Journalism. Report available at

https://reutersinstitute.politics.ox.ac.uk/sites/default/files/E ditorial\%20analytics\%20-\%20how\%20news\%20media\%2 0are\%20developing\%20and\%20using\%20audience\%20dat a\%20and\%20metrics.pdf

[13] McLeod, D. M., Eveland, W. P., \& Nathanson, A. I.

(1997). Support for censorship of violent and misogynic rap lyrics an analysis of the third-person effect. Communication Research, 24(2), 153-174.

[14] Salwen, M.B. (1998). Perceptions of media influence and support for censorship the third-person effect in the 1996 presidential election. Communication Research, 25(3), 259285.

[15] Gunther, A.C., \& Thorson, E. (1992). Perceived persuasive effects of product commercials and public service announcements: Third-person effects in new domains. Communication Research, 19, 574-596.

[16] Henriksen, L. \& Flora, J.A. (1999). Third-person perception and children: Perceived impact of pro- and antismoking ads. Communication Research, 26(6), 643-665. [17] Gunther, A.C. (1995). Overrating the X-rating: The thirdperson perception and support for censorship of pornography Journal of Communication, 45(1), 27-38.

[18] Salwen, M.B., \& Dupagne. M. (1999). The third-person effect: Perceptions of the media's influence and immoral consequences. Communication Research, 26, 523-549. [19] Pan, Z., Abisaid, J.L., Paek, H.J., Sun, Y., \& Houden, D. (2006). Exploring the perceptual gap in perceived effects of media reports of opinion polls. International Journal of Public Opinion Research, 18(3), 340-350.

[20] Sun, Y., Shen, L., \& Pan, Z. (2008). On the behavioral component of the third-person effect. Communication Research, 35(2), 257-278.

[21] Gunther, A. C., \& Christen, C. T. (2002). Projection or persuasive press? Contrary effects of personal opinion and perceived news coverage on estimates of public opinion. Journal of Communication, 52(1), 177-195.

[22] Gunther, A. C., \& Storey, J. D. (2003). The influence of presumed influence. Journal of Communication, 53(2),

199 215.

[23] Antonopoulos, N., Veglis, A., Gardikiotis, A., Kotsakis, R., \& Kalliris, G. (2015). Web third-person effect in structural aspects of the information on media websites. Computers in Human Behaviors, 44, 48-58.

[24] Fu, W. W., \& Sim, C. C. (2011). Aggregate bandwagon effect on online videos' viewership: Value uncertainty, popularity cues, and heuristics. Journal of the American Society for Information Science and Technology, 62(12), 2382-2395.

[25] Festinger, L. (1954). A theory of social comparison process. Human Relations, 7(1), 117-140.

[26] Marsh, C. (1984). Back on the bandwagon: The effect of opinion polls on public opinion. British Journal of
Political Science, 15, 51-74.

[27] Chaiken, S. (1987). The heuristic model of persuasion. In M.P. Zanna, J.M. Olson, C.P. Herman (Eds.), Social influence: The Ontario symposium (Vol. 5, pp. 3-39). Hillsdale, NJ: Erlbaum.

[28] Lapinski, M. K. \& Rimal. R.N. (2005). An Explication of Social Norms. Communication Theory, 15(2), 127-147.

[29] Perloff, R. M. (1999). The third person effect: A critical review and synthesis. Media Psychology, 1(4), 353-378. [30] Tewksbury, D., Moy, P., \& Weis, D. S. (2004).

Preparations for Y2K: Revisiting the behavioral component of the third-person effect. Journal of Communication, 54, 138-155.

[31] Wei, R., Lo, V. H., \& Lu, H. Y. (2008). Third-person effects of health news: Exploring the relationship among media exposure, presumed media influence, and behavioral intentions. American Behavioral Scientist, 52, 261-277. http://dx.doi.org/10.1177/0002764208321355.

[32] Lee, E. J., \& Shin, S. Y. (2014). When the medium is the message: How transportability moderates the effects of politicians' Twitter communication. Communication Research, 41(8), 1088-1110.

[33] Reid S., Giles H. and Harwood J., A self- categorization perspective on communication and intergroup relations, In J. Harwood and H. Giles, (Eds.), Intergroup communication (pp. 241-263), New York: Peter Lang.

[34] Baumeister, R.F. \& Leary, M.R. (1995). The need to belong: Desire for interpersonal attachments as a fundamental human motivation. Psychological Bulletin, 117(3), 497-529.

[35] Cialdini, R. B., Kallgren, C. A., \& Reno, R. R. (1991). A focus theory of normative conduct: theoretical refinement and reevaluation of the role of norms in human behavior. Advances in Experimental Social Psychology, 24(20), 1-243. [36] Pickett, C. L., Gardner, W. L., \& Knowles, M. (2004). Getting a cue: The need to belong and enhanced sensitivity to social cues. Personality and Social Psychology

Bulletin, 30(9), 1095-1107.

[37] Leary, M.R., Kelly, K.M., Cottrell, C. \& Schreindorfer, L.S. (2013). Individual differences in the need to belong: mapping the nomological network. Journal of Personality Assessment, 95(6), 610-624.

[38] Bryant, J., \& Miron, D. (2002). Entertainment as media effect. In J. Bryant \& D. Zillmann (Eds.), Media effects:Advances in theory and research (2nd Eds., pp. 549 582). Mahwah, NJ: Erlbaum.

[39] Rhodes, N., \& Ellithorpe, M. E. (2016). Laughing at Risk: Sitcom Laugh Tracks Communicate Norms for Behavior. Media Psychology, 1-22.

[40] Walther, J. B., \& Jang, J. W. (2012). Communication processes in participatory websites. Journal of ComputerMediated Communication, 18(1), 2-15. 
Figure 1. Sample Stimuli
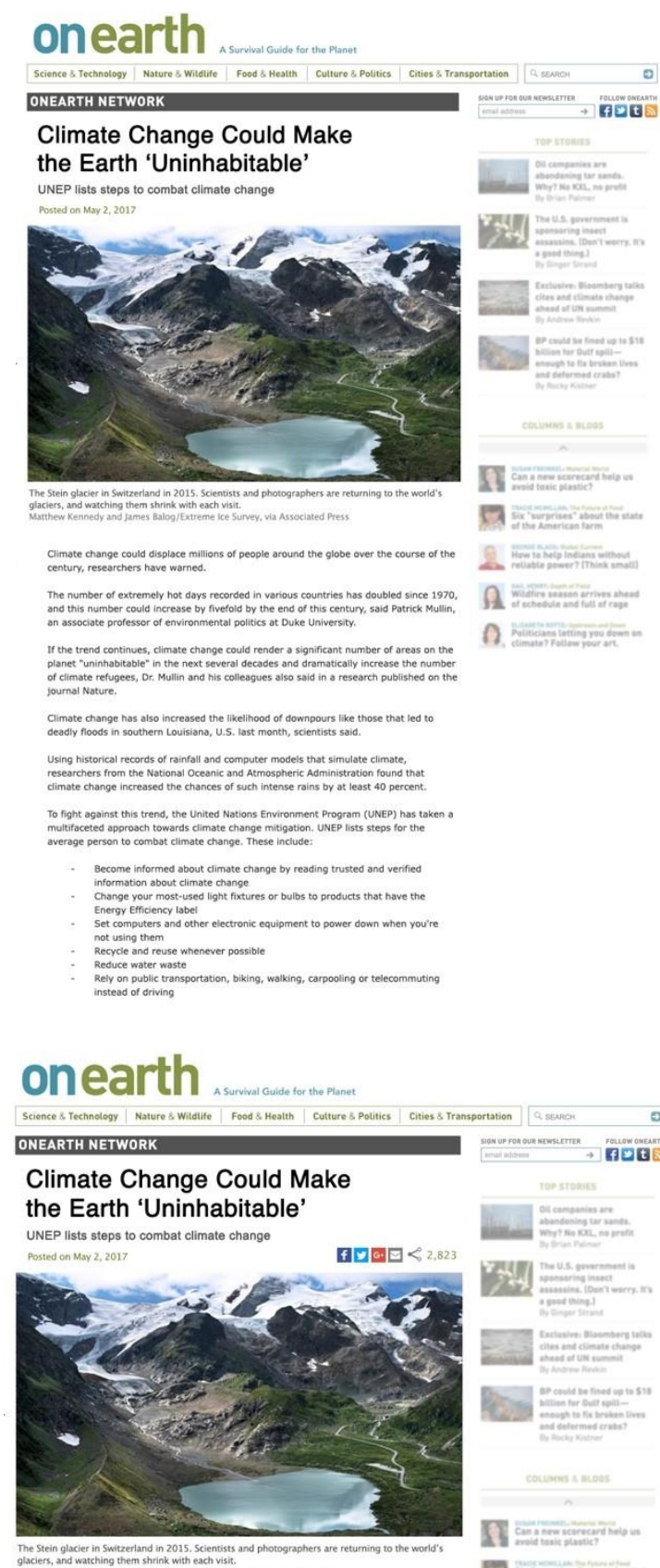

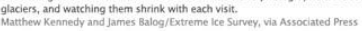

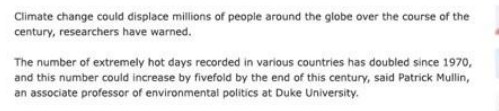

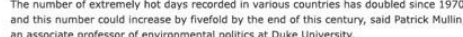

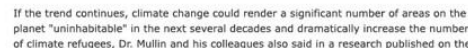

asever o

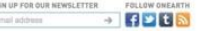

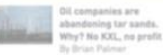

त्रता

Sald

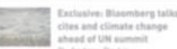

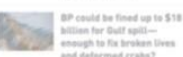

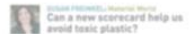

田

2.

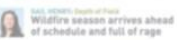

ก.

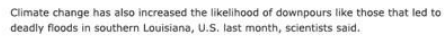

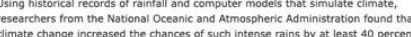

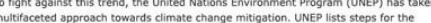

overage person to combat cilimate change. These inculue;

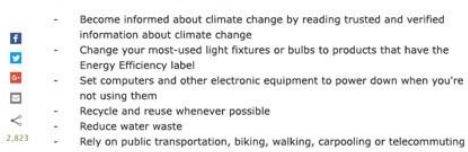

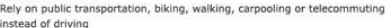




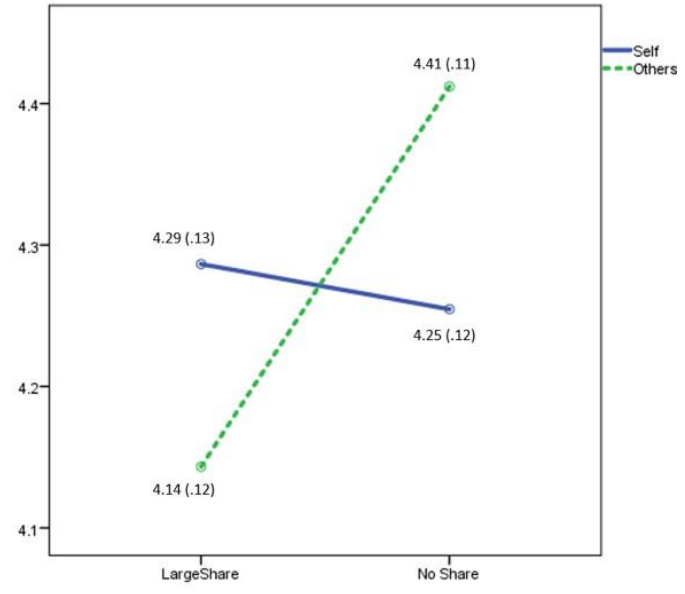

Figure 2. Third-person perceptions as a function of social media metrics. Note. $F(1,239)=$ $5.30, p<.05$, partial $\eta^{2}=.02$. Numbers in parentheses represent standard errors.

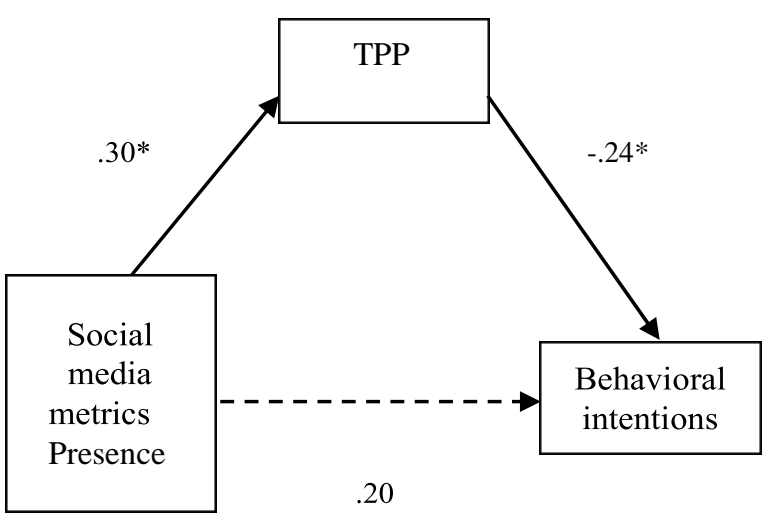

Figure 3. Effects of social media metrics on behavioral intentions. The no social media condition served as a reference; ${ }^{*} p<.05$.

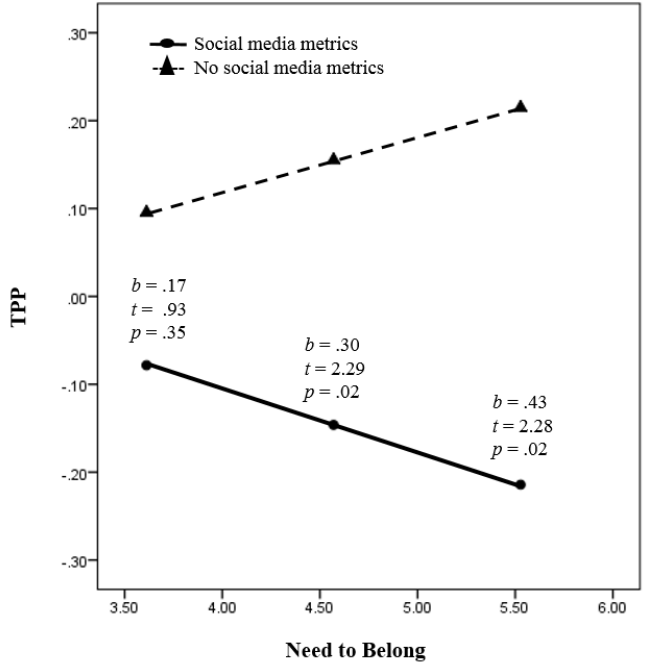

Figure 4. Conditional effects of social media metrics on TPP: Need to belong as a moderator. Note: $t$-values are for the difference in estimated TPP scores between the absence and presence of social media metrics at $-1 \mathrm{SD}$, mean score, and +1 SD of need to belong. 